DOCTRINA

\title{
El reconocimiento del estatuto de refugiado por motivo de violencia basada en el género durante situaciones de conflicto armado
}

\author{
Gender-based violence in armed conflicts and the recognition of the refugee status
}

\section{Sabrina Paula Vecchioni}

Universidad de Buenos Aires, Argentina

\begin{abstract}
RESUMEN La definición clásica de refugiado ha sido puesta a prueba por los eventos de un mundo en constante cambio frente a la necesidad de protección internacional cuando aquella proporcionada por el Estado de nacionalidad o de residencia habitual no resulta efectiva. Los desplazamientos masivos de población originados por conflictos armados pusieron a prueba el estatuto de refugiado a partir de interpretaciones regionales que amplían los supuestos de protección internacional. Sumado a ello, vale señalar el desarrollo, por parte de las teorías feministas, respecto a la violencia basada en el género en dichos contextos. En este trabajo analizamos la complementariedad del derecho internacional de los derechos humanos y el derecho internacional humanitario a la luz del derecho internacional de los refugiados, con el fin de establecer la plena e irrestricta vigencia de la protección internacional en los casos de mujeres forzadas a desplazarse de sus países de origen, como consecuencia de una situación de conflicto armado.
\end{abstract}

PALABRAS CLAVE Estatuto de refugiado, conflictos armados, violencia basada en el género.

ABSTRACT The common definition of refugee has been put to test by the events of a world in constant change, with regards to the need for international protection when that provided by the State of nationality or habitual residence is not effective. Mass displacement of people caused by armed conflicts put the refugee status to the test on the basis of regional interpretations that broaden the scope of international protection. In addition, we must consider the development of feminist theories on gender-based violence during armed conflicts. The purpose of this paper is to discuss and analyze the complementarity of International Human Rights Law and International Humanitarian Law and their relation with International Refugee Law, in order to establish the full and 
unrestricted validity of international protection in cases of displaced women, as a consequence of armed conflict.

KEYWORDS Refugee status, armed conflicts, gender-based violence.

Nos enfrentamos a la mayor crisis de refugiados y desplazamiento de nuestro tiempo. Y, sobre todo, esta no es solamente una crisis de números; es también una crisis de solidaridad.

BAN KI-MOON ${ }^{1}$

Tras vivir los horrores de la guerra en Irak y Siria, estas mujeres lo han arriesgado todo con tal de conseguir seguridad para ellas y para sus hijos. Pero desde el mismo momento en que comienzan su viaje vuelven a verse expuestas a sufrir violencia y explotación, sin recibir apenas apoyo o protección.

Tirana Hassan ${ }^{2}$

\section{Introducción}

Los conflictos armados y sus devastadoras consecuencias han acompañado el desarrollo de la historia mundial desde tiempos inmemoriales, al igual que las diversas violaciones y abusos cometidos contra las mujeres durante éstos. Numerosos relatos históricos muestran la crueldad de los ejércitos hacia las mujeres como una forma de debilitar al enemigo y forzarlo a su rendición (Naciones Unidas, 1995: 3).

En la antigua Roma se señala el secuestro y abuso de doncellas en el tristemente célebre episodio conocido como «El rapto de las sabinas», en el que se describe:

Roma era ya tan fuerte, que su potencial bélico estaba a la altura del de cualquiera de los Estados vecinos; [...] se puso en marcha según lo previsto el golpe de fuerza: a una señal dada, los jóvenes romanos se lanzan a raptar a las doncellas. La mayoría de ellas fueron cogidas al azar por el primero que las tuvo a la mano; algunas, especialmente hermosas, reservadas a los senadores más importantes, eran llevadas a casa de éstos por los plebeyos a los que se les había encomendado esta misión (Livio, 1990: 180-181).

1. Centro de Noticias de Naciones Unidas, «Refugee crisis about solidarity, not just numbers, secretary-general says at event on global displacement challenge» (SG/SM/17670-REF/1228), del 15 de abril de 2016. Disponible en http://bit.ly/2d9wkij.

2. Amnistía Internacional, «Las refugiadas sufren agresiones físicas, explotación y acoso sexual al atravesar Europa», publicada el 18 de enero de 2016. Disponible en http://bit.ly/2bYcO5z. 
En la actualidad, el nivel de hostilidad armada se traduce en la creciente necesidad de aniquilar a la población civil atrapada en la geografía donde se desarrollan los combates, por lo que es innegable la utilización de la violencia basada en el género, incluyendo la violencia física en todas sus formas, como una eficaz táctica de guerra y terrorismo. La raza, etnia, pertenencia religiosa o la sola condición de mujer constituyen un elemento válido de ataque por parte de grupos armados, miembros de las fuerzas armadas regulares de los Estados y otros actores no estatales, y su utilización en el conflicto como un medio de combate no regulado ni permitido contra el enemigo (Consejo de Seguridad, 2016b: 1).

Según las cifras oficiales del Alto Comisionado de las Naciones Unidas para los Refugiados (ACNUR), en 2015:

El desplazamiento forzado global [había] aumentado [...], alcanzando una vez más niveles sin precedentes. Al término del año, había 65,3 millones de personas desplazadas forzosamente en todo el mundo a consecuencia de la persecución, los conflictos, la violencia generalizada o las violaciones de derechos humanos. Esto son 5,8 millones de personas más que el año anterior (59,5 millones) (ACNUR, 2015: 2).

Para 2015, el conflicto en la República Árabe Siria transcurría su quinto año consecutivo recibiendo una atención mundial significativa debido a los grandes desplazamientos de refugiados, mayormente hacia Europa, y a las necesidades humanitarias generadas (ACNUR, 2015: 6). Se suman a ello las diversas crisis humanitarias y conflictos no resueltos, como aquellos surgidos a lo largo de 2015 en Burundi, Irak, Libia, Níger y Nigeria, y la reactivación de las crisis no resueltas de Afganistán, la República Centroafricana, la República Democrática del Congo, Sudán del Sur y Yemen. La consecuencia inmediata fue 1,8 millones de nuevos refugiados desplazados, frente a los 1,2 millones registrados en 2014: «Durante 2015 fueron desplazadas de sus hogares una media de veinticuatro personas por minuto en el mundo, frente a las treinta personas por minuto hace un año, que sigue siendo la cifra más alta registrada» (ACNUR, 2015: 6).

La realidad señalada nos permite observar la necesidad de una participación activa de los Estados a los fines de garantizar el pleno acceso a los procedimientos de determinación de la condición de refugiado, en particular de las mujeres que son forzadas a dicho desplazamiento cuando en sus países de origen se verifica una situación de conflicto armado.

Siguiendo la propuesta referida, la hipótesis central del presente artículo es el análisis de las relaciones intrínsecas existentes entre los desarrollos normativos del derecho internacional de los derechos humanos, el derecho internacional humanitario, y el derecho internacional de los refugiados, en particular, en los casos de solicitudes del reconocimiento de la condición de refugiado de mujeres y por motivos de violencia basada en el género en el marco de un conflicto armado. 
Para ello deberemos, en principio, establecer el marco teórico conceptual respecto a qué consideraremos como género en el presente trabajo, al analizar el desarrollo de los movimientos feministas, los cuales, luego de las luchas suscitadas en las décadas de los sesenta y setenta en Europa y los Estados Unidos, logran la inclusión del tratamiento de las mujeres como sujetos de derechos en los marcos normativos internacionales de protección de derechos humanos en el ámbito de las Naciones Unidas y, también, a nivel regional en el sistema interamericano. No podemos hacer a un lado la presencia de estándares propios de los denominados feminismos hegemónicos dentro de cuerpos normativos ampliamente masculinos.

Lo expuesto permitirá introducir el enfoque de género, según se desarrollará seguidamente, en el análisis propuesto, a los fines de lograr la plena vigencia de la protección internacional que los Estados se comprometieron brindar a toda persona que se ve forzada a huir de su país de origen por una situación de conflicto armado.

\section{Un acercamiento a la violencia basada en el género en el contexto de los conflictos armados}

Las guerras han llevado consigo el ataque sobre las mujeres y la utilización de sus cuerpos e identidades como un arma poderosa tendiente a devastar al enemigo. No es necesario remontarnos a relatos históricos de la antigua Grecia o Roma, dado que su evolución y utilización constante resulta innegable.

Entre los ejemplos históricos recientes podemos mencionar lo que se dio en llamar el fenómeno de las «mujeres confort», esclavas sexuales al servicio del ejército japonés durante la Segunda Guerra Mundial. Se estima que entre ochenta mil y doscientas mil mujeres, en su mayoría coreanas, fueron víctimas de violencia sexual en burdeles militares japoneses extendidos por toda Asia antes y durante el conflicto, establecidos para elevar la moral de las tropas y evitar que se produjeran abusos sexuales en forma descontrolada en los territorios ocupados por dicho ejército, tras la experiencia de la masacre de Nankín en 1937, durante la cual decenas de miles de mujeres fueron violadas a manos de las tropas japonesas (Chung, 2010). Asimismo, se estima que aproximadamente setenta mil mujeres pudieron ser víctimas de violencia sexual durante la partición del subcontinente que dio lugar a la creación de India y Pakistán como Estados independientes en 1947 (Menon y Bhasin, 1998: 67).

Lo mismo ocurrió en Bangladesh, donde entre doscientas mil y cuatrocientas mil mujeres fueron víctimas de violencia sexual durante el conflicto que dio lugar a la creación del Estado independiente en 1971. La mayoría de ellas eran mujeres bengalíes agredidas por soldados pakistaníes en lo que se concluyó era una estrategia organizada para sembrar el terror en la población de Pakistán Este. No conformes con los abusos sexuales, muchas de estas mujeres fueron luego asesinadas (Saikia, 2004). 
En la historia reciente no podemos dejar de mencionar los abusos cometidos contra mujeres en el conflicto armado de la antigua Yugoslavia, donde la práctica de violencia sexual contra las mujeres se tradujo en fenómenos aún más cruentos, como la implementación de "campos de violación», donde las mujeres, además de sufrir abusos físicos concretos, eran forzadas a participar de las violaciones de otras mujeres desconocidas o miembros de sus familias, embarazos forzados y mutilaciones (Bastick, Grimm y Kunz, 2007: 113-125; Skjelsbaek, 2010: 15-28).

Las prácticas referidas también se han hecho presentes en el conflicto armado en Siria, donde diversos informes de las Naciones Unidas y de organizaciones no gubernamentales de dicho país han establecido la utilización de la violencia sexual contra mujeres, hombres y niños considerados «enemigos» por los bandos en combate. Entre las prácticas utilizadas se destacan violaciones, desnudos prolongados, electroshock en genitales, tocamientos, amenazas de agresión a familiares y observación forzosa de los abusos a otras personas detenidas. Se estiman que unas seis mil mujeres habían padecido violaciones en el marco del conflicto, en muchos casos con embarazos no deseados como consecuencia de estas violaciones (Nasar, 2013: 12-21).

El efecto de las situaciones descritas, con atención a las normas culturales y religiosas de las sociedades afectadas, no es otro que la discriminación hacia las víctimas por parte de familiares y amigos ${ }^{3}$, por lo que no pueden integrarse a sus núcleos de vida luego de los eventos traumáticos (Federación Internacional de Derechos Humanos, 2013: 9-15).

Atendiendo al panorama descrito y al tema propuesto en el presente artículo, resulta necesario establecer el significado que se otorgará a las distintas categorías jurídicas a analizar y su relación con los marcos normativos aplicables para una situación de conflicto armado.

Dada la extensión del presente artículo y el objetivo del análisis propuesto, al hablar de «género» como marco teórico conceptual dentro de los marcos normativos internacionales a los que haremos mención, debemos tener presente su referencia al desarrollo de los denominados feminismos hegemónicos ${ }^{4}$, corrientes promotoras de un sujeto mujer blanco occidental, en contraposición al desarrollo posterior de las

3. Las víctimas de violaciones durante situaciones de conflicto armado presentan cuatro tipos de traumas: «i) Médico (incluyendo lesiones a órganos, VIH, pérdida de la virginidad y embarazos no deseados); ii) psicológicos (miedo, ansiedad, enojo, agresión, culpa, aislamiento, vergüenza, pérdida de confianza y rituales de higiene); iii) psiquiátricos (estrés postraumático, depresión, melancolía, neurosis y desórdenes psicosomáticos), y iv) sociales (estigmatización y repudio)». Sentencia del caso Fiscal con Jean-Pierre Bemba Gombo, Corte Penal Internacional, ICC-01/05-01/08, 21 de junio de 2016, párrafo 36.

4. Compartimos, así, la postura de los denominados feminismos descoloniales centrados en el análisis del «género» en contraposición al «Género», este último entendido como un concepto enfocado en el estudio y análisis de un sujeto mujer blanca occidental universalizante, en amplia omisión a las realidades de las mujeres de otras geografías. 
corrientes feministas descoloniales (Federación Internacional de Derechos Humanos, 2013: 9-15).

Cuando nos referimos a "género», el ACNUR lo ha definido como «la relación entre hombres y mujeres basada en la identidad, las condiciones, las funciones y las responsabilidades según han sido construidas y definidas por la sociedad y la cultura, asignadas a uno y otro sexo» (ACNUR, 2002: 2).

Los aspectos naturales del género, y los procesos naturales del sexo y la reproducción son sólo un telón de fondo, sugerente y ambiguo, de la organización cultural del género y la sexualidad. Qué es el género, qué es un hombre y qué es una mujer, qué relaciones existen o deberían existir entre ellos [...], estos interrogantes no sólo se plantean a partir de los hechos biológicos reconocidos, sino que son también, en gran parte, productos de procesos sociales y culturales (McDowell, 2000: 30).

Surge, así, con mayor fuerza el significado de la categoría de análisis género y su entendimiento, según palabras de Simone de Beauvoir ${ }^{5}$, en cuanto a que la mujer no nace como tal por su identidad sexo biológica, sino que se hace, como producto del contexto social, político, religioso, económico y familiar en el que se encuentra inserta desde su nacimiento y a lo largo de su vida.

Como observamos de los hechos citados ut supra, en el marco de un conflicto armado, la violencia contra las mujeres adopta diversas formas, como asesinatos, abusos físicos, embarazos forzados, esclavitud sexual, mutilaciones, entre otros, con el objetivo de sembrar el terror entre la población civil. Así, se presenta de manera sistemática como un método de combate ${ }^{6}$ con el fin de destruir el tejido social del enemigo, por lo que dichos actos han sido tipificados como crímenes de lesa humanidad o crímenes de guerra ${ }^{7}$ por el derecho penal internacional.

5. Entrevista a Simone de Beauvoir, «Por qué soy feminista» en el programa Questionnaire, de 1975. Disponible en https://youtu.be/txYJ8koZDRI.

6. Los términos «medios y métodos de combate» designan las herramientas utilizadas en los conflictos armados y las maneras en que son utilizadas. El Protocolo Adicional a los Convenios de Ginebra del 12 de agosto de 1949, relativo a la protección de las víctimas de los conflictos armados internacionales, del 8 de junio de 1977, se refiere alternadamente a «métodos o medios de hacer la guerra» (artículos 35.1, 35.3, 51.5.a y 55.1), «métodos y medios de guerra» (título 3 y sección 1 del título 3), «medios y métodos de ataque» (artículo 57.2.a.ii) y «arma, medio o método de guerra» (artículo 36). La violencia sexual asociada al género de la víctima constituye un «arma de guerra», según la jurisprudencia internacional en la materia. Véase Sentencia del caso Fiscal con Jean Paul Akayesu, Tribunal Penal Internacional para Ruanda, rol ICTR-96-4-T, 2 de septiembre de 1998; y Consejo de Seguridad (2008; 2016b).

7. Conforme al Estatuto de la Corte Penal Internacional tipifica en su artículo 7 el crimen de lesa humanidad como: "Cualquiera de los actos siguientes cuando se cometa como parte de un ataque generalizado o sistemático contra una población civil y con conocimiento de dicho ataque: [ ] violación, esclavitud sexual, prostitución forzada, embarazo forzado, esterilización forzada u otros abusos sexuales de gravedad comparable», y por crimen de guerra: «Cometer actos de violación, esclavitud sexual, pros- 
Por su parte, es dable preguntarnos a qué nos referimos con la categoría jurídica de «conflicto armado». El primer acercamiento está dado por la noción histórica de guerra, entendida como un estado de beligerancia u hostilidad armada entre dos o más Estados soberanos, debidamente declarada y conducida de acuerdo con las normas propias, finalizada cuando las potencias vencedoras logran la suscripción de un tratado de paz o armisticio (Gutiérrez Posse, 2014: 15-30).

Entendida antiguamente como la forma natural en que los Estados solucionaban sus controversias mediante el recurso ilimitado a la fuerza armada, con el correr del tiempo, la evolución de las armas empleadas en los combates, sumado a las devastadoras consecuencias para las naciones, hace que surja después de 1945 la prohibición de dicho empleo de la fuerza de manera desmedida y su regulación en las definiciones de los Convenios de Ginebra de 1949. Este documento introduce la categoría jurídica de conflicto armado, tanto en su faz internacional como no internacional, con lo que hace a un lado los rigorismos técnicos a fin de lograr la aplicación irrestricta de la normativa de protección adoptada en la materia desde la creación del Comité Internacional de la Cruz Roja en 1864 (Comité Internacional de la Cruz Roja, 2008).

Las referencias precedentes deben contextualizarse dentro de la evolución de los marcos normativos en análisis a lo largo de la última mitad del siglo XIX, todo el siglo XX y lo que va del siglo XXI. Lo que nos lleva a un análisis que promueve la conciliación entre las definiciones de género, respecto de aquellas consideraciones propias del derecho internacional de los refugiados, el derecho internacional humanitario y el derecho internacional de los derechos humanos, las que muchas veces en aras de la promoción de estándares de protección, hacen a un lado debates profundos acerca del concepto en análisis, como producto de los momentos históricos que signaron las creaciones de sus contenidos normativos.

En este sentido, no podemos hacer a un lado el hecho de que los principales desarrollos de estas tres ramas del derecho internacional se adoptaron en momentos históricos en que las categorías jurídicas se encontraban estrechamente imbuidas de la óptica propia de la concepción masculina sobre el rol de la mujer en la sociedad. El derecho internacional humanitario, si bien desde sus primeros desarrollos normativos en 1864 establecía normas básicas de protección de las mujeres — tanto civiles como de aquéllas incluidas en los cuerpos médicos militares-, responde, al igual que la normativa del derecho internacional humanitario y su definición de refugiado, a la idea de un sujeto de derecho masculino (Butler, 1990: 270-282). Realidad que atraviesa también a los desarrollos en materia de derecho internacional de los derechos humanos posteriores a la adopción de la Declaración Universal de Derechos Humanos de 1948.

titución forzada, embarazo forzado [ ], esterilización forzada y cualquier otra forma de violencia sexual que constituya una violación grave de los Convenios de Ginebra» (artículo 8) (Naciones Unidas, 2002). 
Este aparente cambio de paradigma no surge de manera espontánea, sino como producto de la introducción en el escenario del derecho del debate social y teórico feminista de los años sesenta y setenta, a los fines de quebrar la dicotomía entre lo público y privado, cuya consecuencia inmediata era la separación de hombres y mujeres, que entendía que estas últimas debían cumplir con roles de cuidado asociados a una fragilidad sexo-biológica elaborada y promovida por el sistema patriarcal y, por lo tanto, era natural su exclusión del ámbito público, como de su concepción como sujetos de derecho (Patentan, 1996).

Uno de los cambios referidos sucede en el ámbito de las Naciones Unidas, con la adopción de la Convención sobre la Eliminación de Todas las Formas de Discriminación contra la Mujer (adoptada el 18 de diciembre de 1979), junto con la celebración periódica de conferencias internacionales tendientes a la actualización de las problemáticas de las mujeres en diversos contextos, bajo la premisa de que el reconocimiento de derechos en una codificación particular significaba, sin lugar a dudas, reconocer la dignidad humana de las mujeres, asumiendo que antes de ello esto era inexistente.

A pesar de dichos esfuerzos, se sucede la exclusión sistemática del vasto universo de diversas realidades que atraviesan las mujeres en el mundo (Quijano, 2000; Mohanty, 2008; Curiel, 2006; Lugones, 2005, 2008, 2012; Espinosa Miñoso, 2013, 2014), lo que constituye el punto de partida para la inclusión de un enfoque de género asociado al concepto de mujer en los diferentes cuerpos normativos vigentes.

Asumir que la adopción de normativa internacional de protección de los derechos humanos de las mujeres constituía la única solución a una realidad devastadora resulta simplista e irreal. En los años posteriores, continuaron produciéndose numerosas y diversas formas de violaciones de derechos de las mujeres en los conflictos armados. En la Declaración y Plataforma de Acción de Beijing, se mencionan, entre otras:

Asesinato, terrorismo, torturas, desapariciones involuntarias, esclavitud sexual, violaciones, abusos sexuales y embarazos forzados en situaciones de conflicto armado, especialmente como resultado de políticas de depuración étnica y otras formas de violencia nuevas e incipientes. Ello se ve agravado por las traumáticas consecuencias de carácter social, económico y psicológico causadas por los conflictos armados y la ocupación y dominación extranjeras, consecuencias que se sufren durante toda la vida (Naciones Unidas, 1995: 135).

Este panorama llevó a un pronunciamiento expreso del Consejo de Seguridad de las Naciones Unidas a través de la adopción de resoluciones tendientes a la incorporación de la perspectiva de género en la interpretación, no solo de la normativa del derecho internacional humanitario (los cuatro Convenios de Ginebra de 1949 y sus Protocolos Adicionales de 1977), sino también de la normativa del derecho interna- 
cional de los refugiados. Esto, atendiendo a la particular situación de vulnerabilidad en la que son colocadas las mujeres y los niños en situaciones de conflicto armado, quienes son forzados a desplazarse como producto del temor a la violación de sus derechos, o luego de que dichas violaciones hayan sido cometidas. Todo ello en el entendimiento de que cada esfuerzo tendiente a la protección de la mujer contribuye al esfuerzo por mantener la paz y seguridad internacionales (Consejo de Seguridad, 2000, 2008, 2009a, 2009b, 2010, 2013a, 2013b).

\section{Violencia basada en el género y su inclusión en el derecho internacional humanitario}

La confluencia entre las normas y los debates teóricos respecto del género llevaron a la inclusión de los desarrollos propuestos por los movimientos feministas dentro de la normativa del derecho internacional humanitario, a través de los esfuerzos del Comité Internacional de la Cruz Roja, en un documento titulado «Guía práctica para responder a las necesidades de las mujeres afectadas por conflictos armados», en el que se establece que el concepto género alude al comportamiento culturalmente esperado de hombres y mujeres en relación con papeles, actitudes y valores que se les atribuyen en función de su sexo, mientras que el término «sexo» hace referencia a las diferencias biológicas y físicas (Comité Internacional de la Cruz Roja, 2006; 7).

Hilary Charlesworth señala que «el término género [...] se refiere a la interpretación social de las diferencias entre hombres y mujeres como conceptos de 'femineidad' y 'masculinidad': el excedente de bagaje cultural asociado con el sexo biológico" (Charlesworth, 1999: 379). Mientras que Sandra Whithworth, en referencia a las concepciones feministas del género, refiere que

cuando las feministas usan el término «género», habitualmente lo hacen para señalar que rechazan las categorizaciones esencializadas del hombre y la mujer. Usar el género significa, sin embargo, señalar las formas en que los presupuestos predominantes acerca de la mujer y el hombre, y la femineidad y la masculinidad, definen las condiciones de la vida real de las personas y de las instituciones que crean (y reciben, a su vez, la influencia de éstas). Las feministas sostienen que los presupuestos que prevalecen en cualquier momento o lugar acerca de lo que significa ser hombre o mujer o lo que se considera un comportamiento femenino o masculino apropiado incide en la vida de la gente. Esos presupuestos y esas ideas se pueden utilizar como razones para la exclusión o el privilegio, para imponer disciplina o para justificar y conferir naturalidad a una gran variedad de comportamientos esperados o de opciones de política (Whitworth, 2005: 120).

8. Todos estos documentos del Consejo de Seguridad se encuentran disponibles en http://bit. ly/1ECwWAS. 
En 2007, a instancias del Ministerio de Relaciones Exteriores de Suecia, se celebró una reunión de expertos sobre «Perspectivas de género en torno al derecho internacional humanitario», en la que se buscó ampliar la interpretación de género en el ámbito del derecho internacional humanitario y así conciliar posturas tendientes a su desuso como sinónimo de «mujeres», en el marco de protección necesaria de civiles en un conflicto armado. Se planteó la necesidad de una comprensión más matizada de la aplicación amplia del concepto de género, a fin de garantizar que la protección del derecho internacional humanitario sea lo más sólida posible (Comité Internacional de la Cruz Roja, 2007).

A pesar de los numerosos esfuerzos por dar carácter operativo a estas concepciones y la complejidad que ello implica - puesto que el género resulta una categoría a la vez personal y marcadamente pública-, las definiciones de los roles masculino y femenino en una sociedad determinada suelen recibir la influencia de las instituciones públicas y se encuentran relacionadas con la atribución de poder dentro de las comunidades (Comité Internacional de la Cruz Roja, 2007: 6). El uso del género como categoría de análisis abre el debate sobre la interpretación de las normas sociales (tanto formales como informales) que influyen en las comunidades y sobre el modo en que esos papeles pueden ser modificados, y en la práctica lo son, tanto en tiempos de paz como en situaciones de conflicto armado.

No podemos dejar de mencionar el avance significativo que en la materia se ha dado a partir de la sentencia de la Corte Penal Internacional en el caso Bemba, en el cual por primera vez en la historia del Tribunal el análisis de los crímenes se centró en la consideración como crimen de guerra de las diversas formas de la violencia contra la mujer, además de destacar que la violencia sexual en el contexto de un conflicto armado es utilizada como un arma de guerra con efectos devastadores en la población civil.

Éste es el marco en el cual debemos analizar la particular situación de vulnerabilidad en la que se encuentran hombres y mujeres que se ven forzados a desplazarse de sus países de origen como consecuencia de la violencia en un conflicto armado (ONU Mujeres, 2014).

\section{Violencia basada en el género dentro del derecho internacional de los refugiados}

Como señalamos precedentemente, la consideración de las mujeres como sujetos de derecho necesitados de protección internacional dentro del marco de los desplazamientos forzados no surge de la definición del estatuto de refugiado brindada por la Convención sobre el Estatuto de los Refugiados de 1951 y su Protocolo Adicional de 1967 (Naciones Unidas, 1951, 1967), los que reflejaban un concepto masculino acerca de quién debía ser reconocido en dicho estatuto de protección internacional por los Estados signatarios. 
La inclusión de la perspectiva de género dentro del derecho internacional de los refugiados sigue los mismos procesos reseñados ut supra respecto del derecho internacional humanitario. Con numerosos y variados desarrollos dentro del Comité Ejecutivo del ACNUR $(1985,1993,1995,1996,1997)^{9}$ no fue hasta el 2002 que se adoptó un documento titulado «Directrices sobre protección internacional: La persecución por motivos de género en el contexto del artículo 1A.2 de la Convención de 1951 sobre el Estatuto de los Refugiados, y/o su Protocolo de 1967» (ACNUR, 2002), el cual reinterpretaba la definición de refugiado contenida en los instrumentos internacionales, para los casos en que las mujeres solicitaran asilo como consecuencia de las diversas formas de violencia basada en su género a la que eran sometidas en sus países de origen.

Una de las cuestiones más significativas de las Directrices es la forma en la que se introduce la necesidad de reinterpretación de la denominada definición clásica de refugiado contenida en la Convención de 1951 y su Protocolo Adicional de 1967, pues se analizó la creciente cifra de mujeres que, en los años posteriores a la adopción de dichos instrumentos, se veían forzadas a desplazarse de sus países de origen producto del «temor fundado de persecución», en referencia a situaciones de violencia basada en su género (ACNUR, 2005: 5-8).

Sin embargo, una de las críticas a estos documentos que constituyen guías de interpretación de los tratados internacionales en materia de determinación de la condición de refugiado, se basa en la nula valoración de las diversas realidades propias que las mujeres viven según sus geografías, sumado al hecho de la necesidad de inclusión en categorías jurídicas que fueron concebidas en momentos históricos ajenos y bajo una óptica estrictamente masculina de protección internacional.

Se deja sentado que no todas las mujeres pueden ser sujetos necesitados de protección internacional bajo el estatuto de refugiado por su sola condición de mujer en una sociedad dada, sino que deberá analizarse cada caso concreto en relación con los elementos de la definición clásica de refugiado (ACNUR, 2002: 1).

\section{Convergencia de protección a las víctimas de violencia basada en el género. Análisis de la normativa del derecho internacional de los refugiados y el derecho internacional humanitario}

Debemos preguntarnos qué sucede entonces con aquellas mujeres forzadas a desplazarse como producto de situaciones de conflictos armados en sus países de origen.

9. En las Conclusiones 87.n (ACNUR, 1999) se «[tomó] nota con reconocimiento de los esfuerzos especiales realizados por los Estados para incorporar la perspectiva del género en las políticas, los reglamentos y las prácticas de asilo; [alentó] a los Estados, al ACNUR y a otras partes interesadas a promover una mayor aceptación de la idea de que la persecución puede guardar relación con el género o practicarse mediante la violencia sexual y a incluir esta idea entre sus criterios de protección». Con posterioridad se adoptaron las Directrices sobre Protección Internacional número 9 (ACNUR, 2012). 
Es en este punto en que, atendiendo a la interpretación propia de la definición clásica de refugiado, surgen a nivel regional documentos internacionales en los que se introduce la ampliación y consiguiente aplicación del estatuto de refugiado en los casos de violaciones generalizadas a los derechos humanos y situaciones de conflicto inter$\mathrm{no}^{10}$, sin atender en un primer momento a las consecuencias que dichas situaciones generaban en las mujeres como sujetos de derecho.

Recién en 2004, y frente al creciente desarrollo del ACNUR, con la adopción de la Declaración y Plan de Acción de México, documento de reinterpretación de la Declaración de Cartagena sobre los Refugiados de 1984, se reconoce:

Que la persecución puede guardar relación con el género y la edad de los refugiados; así como la necesidad de brindar protección y asistencia humanitaria atendiendo a las necesidades diferenciadas de hombres y mujeres, niños y niñas, adolescentes y adultos mayores, personas con discapacidad, minorías y grupos étnicos (OEA, 2004: 3).

Por ello, se obliga a los Estados de la región a la observancia de las particulares necesidades de protección de las mujeres desplazadas como consecuencia de conflictos armados.

A pesar de lo expuesto, las situaciones de violencia basada en el género continuaron sucediéndose a nivel regional. En 2014, a treinta años de la adopción de la Declaración de Cartagena, y a instancias del ACNUR, se adoptó un documento abierto a adhesiones en el que se analizaron los crecientes desafíos en la región en materia de la aplicación de la denominada definición ampliada de refugiado (ACNUR, 2014). En este documento se reconoce y documenta la particular situación de vulnerabilidad de las mujeres desplazadas internamente y de las solicitantes de asilo en los países vecinos, como consecuencia de las violaciones de derecho en el marco de conflictos armados en sus países de origen (ACNUR, 2014: 25-27).

Con posterioridad, el 2 de diciembre de 2016, el ACNUR adoptó las «Directrices sobre protección internacional número 12: Sobre personas que solicitan asilo en situaciones de conflicto armado y violencia dentro del artículo 1A.2 de la Convención

10. La Convención de la Organización para la Unidad Africana (OUA), que rige los aspectos específicos de los problemas de refugiados en África, agrega a las condiciones que definen un refugiado el elemento de las «violaciones masivas de derechos humanos» (OUA, 1969). En el ámbito latinoamericano, los Estados adoptaron en 1984 la Declaración de Cartagena sobre los Refugiados, adoptada por el «Coloquio sobre la protección internacional de los refugiados en América Central, México y Panamá: Problemas Jurídicos y humanitarios», celebrado en Cartagena, Colombia, del 19 al 22 de noviembre de 1984, cuya definición de refugiado extiende la protección a víctimas de «violencia generalizada» y «conflictos internos», en el marco de los crecientes desplazamientos forzados suscitados en la década de 1980 y 1990 en los países del Caribe como consecuencia de los derrocamientos de gobiernos democráticos y los conflictos armados de carácter no internacional que se sucedieron. 
de 1951 y el Protocolo de 1967 en relación con el Estatuto de Refugiado y las definiciones regionales de refugiado», documento destinado a establecer una interpretación uniforme de los cuerpos normativos en análisis frente a una realidad que los pone a prueba de manera constante (ACNUR, 2016).

Cabe destacar que desde la Segunda Conferencia Mundial de Derechos Humanos, realizada en Viena en junio de 1993, tanto el ACNUR como el Comité Internacional de la Cruz Roja buscaron establecer la convergencia y complementariedad de los estándares de protección de derechos dentro de las normativas del derecho internacional de los derechos humanos, el derecho internacional humanitario y el derecho internacional de los refugiados (Naciones Unidas, 1993).

Mediante las directrices señaladas, el ACNUR en 2016 introdujo modificaciones significativas a la interpretación de la definición clásica de refugiado, contenida en la Convención sobre el Estatuto de Refugiado de 1951 y su Protocolo Adicional de 1967, estableciendo que en ningún momento deberá entenderse que la definición de refugiado y sus elementos resultan ajenos a las definiciones del estatuto ampliadas y adoptada bajo distintos desarrollos normativos regionales. Asimismo, señaló que la utilización de las categorías jurídicas de conflicto armado -internacional y no internacional-, tensiones internas y disturbios interiores propios de la normativa del derecho internacional humanitario no implican restricciones en la determinación del estatuto de protección internacional (ACNUR, 2016: 1). De esta manera, se estableció que todas las situaciones de protección internacional en las que resulta vigente el estatuto de refugiado se encuentran contenidas en la definición clásica del estatuto de refugiado de la Convención de 1951 y su Protocolo Adicional de 1967, por lo que cualquier interpretación contraria llevaría a la fragmentación innecesaria de un ordenamiento jurídico homogéneo con objetivos comunes.

En cuanto a las situaciones de violencia basada en el género que provocan los desplazamientos forzados, se reconoció que:

La violencia sexual o basada en el género, la esclavitud sexual y conyugal, el matrimonio forzado son formas de persecución en situaciones de conflicto armado y violencia. La violencia sexual y basada en el género es utilizada como táctica ilegal y criminal, estrategia o política durante situaciones de conflicto armado y violencia, en orden a debilitar al adversario directa o indirectamente, a través de la victimización de las mujeres, niñas, hombres y niños. Más allá de la motivación individual del perpetrador, la violencia sexual o basada en el género puede constituir una parte de la estrategia militar o política para abatir, humillar, aterrorizar o destruir población civil en la persecución de objetivos militares, o derivar en otras formas de discriminación asociadas al género, vinculándose a uno o más de los elementos de la Convención (ACNUR, 2016: 7).

No debe olvidarse que la principal forma en la que se manifiesta la violencia de 
género en el marco de un conflicto armado es a través de la violencia sexual, entendida como:

Actos de naturaleza sexual impuestos por la fuerza o mediante coerción, como la causada por el temor a la violencia, la coacción, la detención, la opresión psicológica o el abuso de poder contra cualquier víctima, ya sea hombre, mujer, niño o niña. Sacar ventaja de un entorno coercitivo o de la incapacidad de la víctima para dar su libre consentimiento es también una forma de coacción. La violencia sexual comprende la violación, la esclavitud sexual, la prostitución forzada, el embarazo forzado, la esterilización forzada o cualquier otra forma de violencia sexual de gravedad comparable (Comité Internacional de la Cruz Roja, 2014).

En el ámbito del desarrollo de las Naciones Unidas, se consideran hechos de violencia sexual relacionados con los conflictos armados:

Incidentes o pautas de violencia sexual [...], es decir, la violación, la esclavitud sexual, la prostitución forzada, los embarazos forzados, la esterilización forzada o cualquier otra forma de violencia sexual de gravedad comparable que se cometa contra las mujeres, los hombres, los niños o las niñas. Estos incidentes o pautas de comportamiento se producen en situaciones de conflicto o posteriores a los conflictos o en otras situaciones motivo de preocupación (por ejemplo, durante un enfrentamiento político). Además, guardan una relación directa o indirecta con el propio conflicto o enfrentamiento político, es decir, una relación temporal, geográfica o causal. Aparte del carácter internacional de los supuestos crímenes, que, dependiendo de las circunstancias, constituyen crímenes de guerra, crímenes de lesa humanidad, actos de genocidio u otras violaciones manifiestas de los derechos humanos, la relación con el conflicto puede ser evidente teniendo en cuenta el perfil y las motivaciones del autor, el perfil de la víctima, el clima de impunidad o la situación de colapso en que se encuentre el Estado en cuestión, las dimensiones transfronterizas o el hecho de que violen lo dispuesto en un acuerdo de cesación del fuego (Villellas y otros, 2016: 5).

En cuanto a las cifras de las situaciones que aquí buscan abordarse, éstas resultan innegables y aterradoras: a nivel global, aproximadamente el $13 \%$ de las mujeres sufrió violaciones a lo largo de su vida, ya sea durante su infancia o en su vida adulta, frente al $3 \%$ de los hombres (Spitzberg, 1999). En el 2002, la Organización Mundial de la Salud señalaba que, en ese año, entre el $5 \%$ y $10 \%$ de los hombres había sufrido violencia sexual durante su infancia, un porcentaje que se elevaba a $20 \%$ en el caso de las mujeres (OMS, 2002). En cuanto a la violencia sexual en contextos de conflicto armado, se ha tendido a centrar la atención en los hombres como perpetradores - y en las mujeres como víctimas-, pese a que también existen casos del uso de la violencia sexual contra hombres en diversos conflictos armados, desde la época de la antigua Persia, las Cruzadas o la guerra sino-japonesa, entre otros (Sivakumaran, 2007). Estudios específicos han documentado hechos de violencia sexual en casos como Chile, Croacia, 
El Salvador, Grecia, Irán, Kuwait, Sri Lanka, República Democrática del Congo, las antiguas Unión Soviética y Yugoslavia, entre otros (Stemple, 2009).

El escenario actual nos lleva a preguntarnos sobre la proporción de mujeres forzadas a desplazarse de sus países de origen producto de la violencia de género en el marco de los conflictos armados. Una dificultad para arribar a una respuesta lo constituye la falta de estadísticas desagregadas. Sin embargo, de la información más reciente se desprende que «la proporción de mujeres entre las personas refugiadas osciló entre el $47 \%$ y el $49 \%$ entre 2003 y 2015" (ACNUR, 2015: 52). Frente a dicho incremento, la respuesta de la comunidad internacional priorizó cuestiones de seguridad nacional por sobre las obligaciones internacionalmente asumidas de protección, y quienes escapaban producto del temor de los hechos de violencia vividos en sus países de origen se encontraron con rutas de migración aún más agresivas y peligrosas, además de sociedades de acogida donde sus situaciones no eran contempladas de acuerdo con los marcos de protección vigentes.

Cabe destacar que la mayor parte de los Estados no contienen en sus estadísticas sobre reconocimiento del estatuto de refugiado información desagregada en cuanto a los motivos de dichos reconocimientos, pues solo guardan una mera referencia numérica basada en el sexo biológico «hombre/mujer», lo que imposibilita la mayoría de las veces un análisis con perspectiva de género como el que busca realizar el presente trabajo.

A pesar de la falta de información concreta y desagregada, el estado de situación descrito vuelve innegable la necesidad de hacer un reconocimiento irrestricto de la protección internacional ajena a un ámbito temporal de vigencia. El ACNUR reconoce que las consecuencias de los actos referidos cometidos durante una situación de conflicto armado o de violencia generalizada no gozan de una vigencia temporal asociada a la duración de las situaciones antes referidas, respecto del reconocimiento del estatuto de refugiado. El temor de persecución, entendido como la posibilidad de volver a ser receptor de dichos actos atroces, deja consecuencias físicas y psicológicas en las víctimas de tales actos, capaces de proyectarse durante toda su vida, lo cual hace intolerable el regreso a su país de origen y hace aún más necesaria la vigencia de la protección internacional del estatuto de refugiado (ACNUR, 2016: 7).

A la luz del análisis precedente, la protección internacional del estatuto de refugiado se extiende a los fines de propender a una interpretación armónica de los marcos normativos con la finalidad de proteger a las víctimas de violencia basada en el género, pues se debiera considerar los diversos desarrollos normativos a nivel interno de cada Estado con el fin de establecer un procedimiento de determinación de la condición de refugiado acorde con la Convención de 1951 y su Protocolo de 1967, con miras a la plena vigencia de la perspectiva de género en consonancia con los desarrollos del ACNUR en la materia" ${ }^{11}$.

11. Como ejemplo podemos mencionar el caso de la República Argentina, donde la Ley General de 
Sin embargo, pretender que ello resulte suficiente para garantizar la mentada protección internacional de las víctimas sería un tanto utópico, pues hay numerosos factores que influyen y atraviesan el desplazamiento forzado de las personas. Será cada caso concreto el encargado de poner a prueba la voluntad de los Estados asumida a nivel internacional y ratificada mediante los mecanismos internos de aplicación de las normas reseñadas.

\section{Conclusiones}

El análisis precedente permite establecer, más allá de las objeciones teórico-feministas, la existencia de un marco normativo internacional complementario de protección conformado por el derecho internacional de los derechos humanos, el derecho internacional humanitario y el derecho internacional de los refugiados. Asimismo, tampoco puede hacerse a un lado la implementación progresiva de la perspectiva de género en los procedimientos internos de reconocimiento del estatuto de refugiado.

Siempre quedará la posibilidad de cuestionar los estándares de protección introducidos a partir del desarrollo de los denominados «feminismos hegemónicos». Sin embargo, resulta innegable su influencia a la hora de determinar no sólo la necesidad de protección de las mujeres en las situaciones descritas, sino también su constitución en sujetos de derecho para los marcos normativos analizados, a los cuales los Estados se han obligado.

En este sentido, se hace necesario más que nunca el estudio continuado y la reinterpretación de las normas existentes con la introducción de los debates teóricos propios de los movimientos feministas, con el fin de consensuar estándares de protección acordes con las necesidades propias de las personas forzadas a desplazarse de sus países en conflicto armado por la violencia basada en el género.

La realidad en la que vivimos torna cada vez más ilusorios los objetivos de las diversas conferencias y plataformas internacionales de trabajo en la materia, en los que se señala a las mujeres como los sujetos de derecho proveedores de paz y seguridad en sus comunidades, lo que lleva implícita la pregunta acerca de si las acciones en su contra no constituyen una forma de perpetuación de la violencia en todas sus formas y la aniquilación de un enemigo que parece estar presente en todas las sociedades.

\footnotetext{
Reconocimiento y Protección al Refugiado establece en su artículo 53 como obligación de la autoridad de aplicación: «[procurar] cuando se tratare de mujeres o menores, en especial si no están acompañados, que hubieren sido víctimas de violencia, la atención psicológica especializada de los mismos, y durante el procedimiento se observará las recomendaciones del ACNUR formuladas en las Guías para la protección de mujeres refugiadas y las directrices sobre persecución por motivos de género. En el caso de los menores se tendrán en cuenta las directrices sobre su protección y cuidado dando cuenta a los organismos con responsabilidad primaria en políticas dirigidas a grupos vulnerables a los fines de una solución eficaz, rápida y de contención efectiva a dichas personas» (Ley 26.165, artículo 53).
} 
Más allá de lo expuesto, debemos atender a la protección existente, que busca la vigencia irrestricta de un núcleo de garantías contra toda situación de violencia basada en el género dentro de un contexto de conflicto armado, y que deja a cargo de los operadores jurídicos la responsabilidad de su aplicación, según el espíritu que guio su adopción y entrada en vigencia de la Convención y su Protocolo, los cuales buscaban dar, según nuestro entendimiento, una respuesta integral a las víctimas los hechos referidos.

\section{Referencias}

ACNUR, Alto Comisionado de las Naciones Unidas para los Refugiados (1985). «Conclusiones número 39: Mujeres refugiadas y protección internacional». Disponible en http://bit.ly/2v6BJzM.

-. (1993). «Conclusiones número 73: Protección de los refugiados y violencia sexual». Disponible en http://bit.ly/2vgskah.

-. (1995). «Conclusiones del Comité Ejecutivo sobre la protección internacional e los refugiados. Número 77: Conclusión general sobre la protección internacional». Disponible en http://bit.ly/2haJMGi.

-. (1996). «Conclusiones del Comité Ejecutivo sobre la protección internacional e los refugiados. Número 79: Conclusión general sobre la protección internacional». Disponible en http://bit.ly/2vhoo6X.

-. (1997). «Conclusiones sobre la protección internacional de los refugiados aprobadas por el Comité Ejecutivo. Número 81: Conclusión general sobre la protección internacional». Disponible en http://bit.ly/2vgXzkI.

-. (1999). «Conclusiones sobre la protección internacional de los refugiados aprobadas por el Comité Ejecutivo. Número 87: Conclusión general sobre la protección internacional». Disponible en http://bit.ly/2w9ugNw.

-. (2002). «Directrices sobre protección internacional: La persecución por motivos de género en el contexto del artículo 1A.2 de la Convención de 1951 sobre el Estatuto de los Refugiados, y/o su Protocolo de 1967». HCR/GIP/o2/o1. Disponible en http://bit.ly/2tO3MEA.

-. (2012). «Directrices sobre protección internacional número 9: Solicitudes de la condición de refugiado relacionadas con la orientación sexual y/o la identidad de género en el contexto del artículo 1A.2 de la Convención sobre el Estatuto de los Refugiados de 1951 y/o su Protocolo de 1967». 23 de octubre de 2012. HCR/ IP/12/09. Disponible en http://bit.ly/2tStZl6.

-. (2014). «Iniciativa Cartagena +30 . La protección internacional y la efectiva integración: Recomendaciones de la sociedad civil frente a las dimensiones actuales del asilo y la apatridia en América Latina y el Caribe». Disponible en http://bit. ly/2vgMihp. 
-. (2015). Tendencias globales, desplazamiento forzado en 2015. Forzados a huir. Ginebra: ACNUR. Disponible en http://bit.ly/2cfweVt.

Bastick, Megan, Karin Grimm y Rahel Kunz (2007). Sexual violence in armed conflict. Ginebra: DCAF.

BUTLER, Judith (1990). «Actos performativos y constitución del género: Un ensayo sobre fenomenología y teoría feminista». En Performing feminisms: Feminist critical theory and theatre (pp. 296-314). Baltimore: Johns Hopkins University Press.

Charlesworth, Hilary (1999). «Feminist methods in international law». The American Journal of International Law, 93 (2): 379-394. DOI: 10.2307/2997996.

Chung, Haeng-Ja (2010). «The comfort women: Sexual violence and postcolonial memory in Korea and Japan by C. Sarah Soh». American Anthropologist, 112 (2): 337338. DOI: 10.1111/j.1548-1433.2010.01239_17.x.

Comité Internacional de LA CrUz RoJa (2007). «International humanitarian law and gender. Report summary, international expert meeting: Gender perspectives on international humanitarian law». Disponible en http://bit.ly/2tSVeMz.

- (2008). «¿Cuál es la definición de 'conflicto armado’ según el derecho internacional humanitario?». Documento de opinión. Disponible en http://bit.ly/1BAVyLL.

-. (2014). «Violencia sexual en conflictos armados: preguntas y respuestas». Comité Internacional de la Cruz Roja. Disponible en http://bit.ly/29uRN5G.

Consejo de Seguridad de Naciones Unidas (1995). «Declaración y Plataforma de Acción de Beijing». Disponible en http://bit.ly/Ns1QHN.

-. (2000). «Resolución 1.325». Disponible en http://bit.ly/2smE6uo.

-. (2008). «Resolución 1.820». Disponible en http://bit.ly/2vhzmLg.

-. (2009a). «Resolución 1.888». Disponible en http://bit.ly/2vhsr4I.

-. (2009b). «Resolución 1.889». Disponible en http://bit.ly/2u7UkqU.

-. (2010). «Resolución 1.960». Disponible en http://bit.ly/2vTON9m.

-. (2013a). «Resolución 2.106».Disponible en http://bit.ly/2tMNtnr

-. (2013b). «Resolución 2.122». Disponible en http://bit.ly/2w9QNcV.

- (2016). «Informe del secretario general sobre violencia sexual en los conflictos». S/2016/361. Disponible en http://bit.ly/2eXx8cK.

Curiel, Ochy (2007). «Crítica postcolonial desde las prácticas políticas del feminismo antirracista». Nómadas, 26: 92-101. Disponible en http://bit.ly/1VZBxcx.

Espinosa MiÑoso, Yurderkys (2013). «Feminismos descoloniales de Abya Yala». En Beatrice Didier, Le dictionnaire desfemmes créatrices. À paraître à l'automne (pp. 309-324). París: Des Femmes-Antoinette Fouque.

-. (2014). «Una crítica descolonial a la epistemología feminista crítica». El Cotidiano, 184: 7-12. Universidad Autónoma Metropolitana Unidad Azcapotzalco Distrito Federal, México. Disponible en http://bit.ly/2we7SDz.

Federación Internacional de Derechos Humanos (2013). Violence against 
Women in Syria: Breaking the silence. París: International Federation for Human Rights.

Gutiérrez Posse, Hortensia (2014). Elementos de derecho internacional humanitario. Buenos Aires: Eudeba, 2014.

Livio, Tito (1990). «El rapto de las sabinas». En Ab urbe condita. Tomo 1. Madrid: Gredos.

Lugones, María (2005). «Multiculturalismo radical y feminismos de mujeres de color». Revista Internacional de Filosofía Política, 25: 61-75. Disponible en http://bit. ly/2u>WIxC.

-. (2008). «Colonialidad y género: Hacia un feminismo descolonial», 13-54. En Walter Mignolo (compilador), Género y descolonialidad (pp. 13-54). Buenos Aires: Ediciones del Signo.

-. (2012). «Subjetividad esclava, colonialidad de género, marginalidad y opresiones múltiples». En Pensando los feminismos en Bolivia (pp. 129-140). La Paz: Conexión Fondo de Emancipaciones.

McDowell, Linda (2000). Gender, identity and place. Understanding feminist geographies. Madrid: Cátedra de la Universitat de Valencia.

Menon, Ritu y Bhasin Kamla (1998). Borders \& boundaries: Women in India's partition. Piscataway: Rutgers University Press.

Mohanty, Chandra (2008). «Bajo los ojos de Occidente. Academia feminista y discurso colonial», p.112-161. En Rosalva Aída Hernández Castillo y Liliana Suárez Navaz (coordinadores), Descolonizar el feminismo: Teorías y prácticas desde los márgenes. Madrid: Cátedra, 2008.

NaCiOnes Unidas (1951). «Convención sobre el estatuto de los refugiados». Disponible en http://bit.ly/2eoFHTu.

—. (1967). «Protocolo sobre el estatuto de los refugiados». Disponible en http://bit. ly/2loEbhg.

-. (1993). «Vienna Declaration and Programme of Action». Disponible en http://bit. ly/1d6qX9P.

-. (1995). «Informe de la Cuarta Conferencia Mundial sobre la Mujer Beijing», 4 a 15 de septiembre de 1995. A/CONF.177/20/Rev.1. Disponible en http://bit.ly/1jAwKqT.

NASAR, SEMA (2013). Violence against women, bleeding wound in the Syrian conflict. Copenhague: Euro-Mediterranean Human Rights Network.

ONU Mujeres (2014). «Recomendaciones generales adoptadas por el Comité para la eliminación de la discriminación contra la mujer». Disponible en http://bit.ly/ VoLxjn.

OEA, Organización de los Estados Americanos (2004). «Declaración y Plan de Acción de México Para Fortalecer la Protección Internacional de los Refugiados en América Latina». Ciudad de México, 16 de noviembre del 2004. Disponible en http://bit.ly/1qOFBuU. 
OMS, Organización Mundial de la Salud (2002). World report on violence and health. Ginebra: OMS.

OUA, Organización de la Unión Africana (1969). «Convención de la OUA por la que se regulan los aspectos específicos de problemas de los refugiados en África». Disponible en http://bit.ly/2eWKQgh.

Patentan, Carole (1996). «Críticas feministas a la dicotomía público/privado». En Carme Castells (compiladora), Perspectivas feministas en la teoría política (pp. 3152). Barcelona: Paidós.

Quijano, Aníbal (2000). «Colonialidad del poder y clasificación social». Journal of World-Systems Research, 6 (2): 342-386. DOI: 10.5195/jwsr.200o.228.

SAIKIA, Yasmin (2004). "Beyond the archive of silence: Narratives of violence of the 1971 liberation war of Bangladesh». History Workshop Journal, 58 (1): 275-287. DOI: $10.1093 / \mathrm{hwj} / 58.1 .275$.

Sivakumaran, Sandesh (2007). «Sexual violence against men in armed conflict». The European Journal of International Law. 18 (2): 253-276. DOI: 10.1093/ejil/chmo13.

SkJelsbaek, Inger (2010). The elephant in the room: An overview of how sexual violence came to be seen as a weapon of war. Oslo: PRIO.

SPITZBerg, Brian (1999). "An analysis of empirical estimates of sexual aggression, victimization and perpetration». Violence and Victims, 14 (3): 241-260.

STEMPLE, Lara (2009). «Male rape and human rights». Hastings Law Journal, 60: 605646. Disponible en http://bit.ly/L2fY9V.

Villellas, Ana y otros (2016). «Violencia sexual en conflictos armados». Quaderns de Construcció de Pau (27): 2-16. Disponible en http://escolapau.uab.es/img/qcp/ QCP27_ViolenciaSexualE.pdf.

Whitworth, Sandra (2005). «Globalizing gender: Who gets it? Who doesn't?». En Christie Ryerson y Elizabeth Dauphine (editores), The ethics of building peace in international relations: Selected proceedings of the Twelfth Annual Conference of the Centre for International and Security Studies (pp. 119-130). Toronto: York Centre for International and Security Studies.

\section{Sobre la autora}

Sabrina Paula Vecchioni es abogada. Diplomada en Ciencias Sociales con mención en Género, Sociedad y Políticas de Flacso-PRIGEPP. Profesora de Derecho Internacional Humanitario, Facultad de Derecho de la Universidad de Buenos Aires. Prosecretaria administrativa de la Comisión para la asistencia integral y protección al refugiado y peticionante de refugio, Ministerio Público de la Defensa, Defensoría General de la Nación, Argentina. Su correo electrónico es svecchioni@gmail.com. 